\title{
Web Enhanced Course, Solusi Bagi Peserta Didik Dalam Pemahaman Materi Perkuliahan
}

\author{
Andy Prasetyo Wati ${ }^{1}$, Sri Handayani ${ }^{2}$ \\ ${ }^{1,2}$ Economic Education Program, Faculty of Economic, Universitas Negeri Malang, Indonesia \\ andy.prasetyo.fe@um.ac.id, sri.handayani.fe@um.ac.id
}

\begin{abstract}
Cognitive abilities in students have an important role for children's success in learning because most of the activities in learning are always associated with problems of remembering and thinking. Cognitive abilities are intended so that children are able to explore the world around them through their five senses, which are collaborated with accurate analysis so that with the understanding of the knowledge they get, children can carry on their lives. In supporting the implementation of learning activities with cognitive abilities so as to produce a maximum level of understanding of lecture material, it is necessary to have an appropriate digital-based learning media so that it can collaborate between technology and cognitive abilities. One of the digital-based learning media that can be applied in supporting students' cognitive abilities is to use Web Enhanced Course (WEC). The method used in this study uses descriptive methods and linear regression. Data obtained from the results of questionnaires that have been filled out by students using simple linear regression analysis techniques. The population used in this study were students of the Faculty of Economics, Universitas Negeri Malang. The population used to measure the level of student understanding of lecture material using the Web Enhanced Course amounted to 284 students, while the sampling technique used was proportional random sampling to obtain a sample of 74 students. While the results of this study can be concluded that the use of digital learning media Web Enhanced Course has an influence on improving understanding of lecture material by students as measured using cognitive abilities.
\end{abstract}

Keywords: web enhanced course, pedagogic, understading

History of Article:

Received : (02-02-2020), Accepted : (05-03-2020), Publised : (24-03-2020)

\section{Citation:}

Wati, A.P., \& Handayani, S (2020) Web Enhanced Course, Solusi Bagi Peserta Didik dalam Pemahaman Materi Perkuliahan. Jurnal Pendidikan Ekonomi, 13(1), 61-68 


\section{PENDAHULUAN}

Penggunaan media pembelajaran dalam proses mengajar dapat membangkitkan keinginan dan minat yang baru, motivasi serta rangsangan dalam melakukan kegiatan belajar pada peserta didik sehingga mengakibatkan adanya peningkatan pemahaman dan hasil belajar peserta didik. Kemampuan dalam memahami materi, memecahkan suatu permasalahan dan pengambilan keputusan yang tepat dan mampu menginterpretasikan melalui analisis yang tajam, tepat dan akurat merupakan kemampuan yang unik dalam berpikir setiap individu sehingga kemampuan seperti ini sering disebut dengan excecutive control. Menurut Yamin (2008) kemampuan kognitif atau kemampuan pemahaman yang dicetuskan oleh Gagne ini dapat diilustrasikan sebagai strategi kognitif berupa analisis, sintesis dan evaluasi yang dapat dipelajari baik oleh pendidik maupun peserta didik. Pelatihan yang dapat dilakukan dalam meningkatan kemampuan ini dapat dapat dilakukan dengan memberikan pelatihan bahan atau materi perkuliahan secara continu dan berjenjang, sehingga peserta didik dapat berlatih dalam memecahkan masalah, baik dalam di dalam kelas maupun di luar kelas.

Kemampuan kognitif merupakan dasar bagi anak untuk memiliki kemampuan dalam berpikir. Jadi proses kognitif berhubungan dengan tingkat kecerdasan (intelegensi) yang menandai seseorang dengan berbagai minat terutama sekali ditujukan kepada ide-ide belajar. Hal ini senada dengan pendapat Piaget bahwa kemampuan berkembang secara bertahap, sejalan dengan perkembangan fisik dan syaraf-syaraf yang berada di pusat susunan syaraf (Abdurrahman, 2012). Sedangkan menurut Susanto (2011) kognitif adalah suatu proses berpikir, yaitu kemampuan individu untuk menghubungkan, menilai, dan mempertimbangkan suatu kejadian atau peristiwa. Kemampuan kognitif pada peserta didik mempunyai peranan penting bagi keberhasilan anak dalam belajar karena sebagian besar aktivitas dalam belajar selalu berhubungan dengan masalah mengingat dan berpikir. Kemampuan kognitif dimaksudkan agar anak mampu melakukan eksplorasi terhadap dunia sekitar melalui panca inderanya yang dikolaborasikan dengan analisis akurat sehingga dengan pemahaman pengetahuan yang didapatkannya tersebut anak dapat melangsungkan hidupnya. Sehingga, menurut Mitasari (2018) setiap peserta didik memiliki kesemoatan untuk dapat mengembangkan segala potensi ang dimilikinya dalam mengembangkan intelektual dan perkembangan kognitifnya di sekolah.

Tetapi pada kenyataannya, Kementerian Pendidikan dan Kebudayaan (2012) menerima laporan dari Trends in International Match Science Survey dari Global Institute (2007) bahwa hasil survey menunjukkan masih rendahnya kemampuan peserta didik dalam berpikir tingkat tinggi. Hal ini ditunjukkan ketercapaian kemamapuan peserta didik Indonesia dalam mengerjakan soal berpikir tingkat tinggi dan advance (reasoning) hanya 5\% dan sebesar 78\% baru dapat mengerjakan soal-soal tingkat rendah (knowing). Hal senada juga dilaporkan oleh PISA yang melakukan survey pada tahun 2009 terhadap kemampuan kognitif peserta didik di Indonesia, hasilnya adalah masih rendahnya kemampuan peserta didik di Indonesia dalam penguasaan materi pelajaran. Hampir seluruh peserta didik di Indonesia hanya menguasai pelajaran sampai level 3, dibandingkan dengan Negara lain yang sudah banyak mencapai level 4 hingga level 6.

Dalam mendukung terlaksananya kegiatan pembelajaran dengan kemampuan kognitif sehingga dihasilkan tingkat pemahaman yang maksimal terhadap materi perkuliahan, maka diperlukan media pembelajaran berbasis digital yang tepat sehingga dapat mengkolaborasikan antara teknologi dan kemampuan kognitif. Priyambodo, Wiyasari dan Sari (2012) berpendapat bahwa penggunaan teknologi sebagai media pembelajaran menjadikan meluasnya kesempatan mahasiswa dalam meningkatkan pembelajarannya. Sedangkan Suwastika (2018) menyatakan bahwa dengan adanya teknologi informasi seperti internet mahasiswa dengan mudah mendapatkan informasi 
yang diperlukan baik untuk tugas dan yang lainnya melalui media internet ini tanpa harus membeli atau membaca buku teks. Salah satu media pembelajaran berbasis digital yang dapat diterapkan dalam menunjang kemampuan kognitif peserta didik adalah dengan menggunakan Web Enhanced Course (WEC). Menurut Sa'ud (2009) WEC merupakan pemanfaatan internet untuk pendidikan, selain itu dapat juga digunakan untuk menunjang peningkatan kualitas belajar mengajar di kelas. WEC ini juga dikenal dengan nama WLC (web lite course), karena kegiatan ini mengutamakan tatap muka dikelas tapi berbasis web. Oleh karena itu, pendidik dituntut untuk menguasai teknik mencari informasi di internet, membimbing peserta didik mencari dan menemukan situs-situs yang relevan dengan bahan pembelajaran, menyajikan materi menarik dan diminati melalui web, melayani bimbingan dan komunikasi melalui internet serta kecakapan lain yang diperlukan.

Dari permasalahan yang terjadi, maka perlu adanya kolaborasi dan pembaharuan dari sisi pendidik dan peserta didik dalam proses belajar mengajar di kelas agar dapat menghasilkan kemamapuan kognitif yang tinggi. Sehingga, dengan menggunakan Web Enhanced Course (WEC) harapannya dapat meningkatkan pemahaman peserta didik terhadap materi perkuliahan. Hal ini senada dengan pernyataan Solihat, Suminawati, Afriza, (2019) yang menyatakan bahwa proses pembelajaran merupakan inti dari proses pendidikan, dimana guru memiliki peranan yang paling penting dalam proses belajar mengajar dan keberhasilan dalam pembelajaran salah satunya ditentukan oleh guru.

\section{METODE}

Metode yang digunakan dalam penelitian ini menggunakan metode deskriptif dan regresi linier. Tujuan dari penggunaan metode ini adalah untuk memperoleh gambaran tentang penggunaan Web Enhanced Course terhadap pemahaman peserta didik yang diukur dari tingkat kemampuan kognitif. Data diperoleh dari hasil kuisioner yang telah diisi oleh mahasiwa dengan menggunakan teknik anlisis regresi linier sederhana. Populasi yang digunakan dalam penelitian ini adalah mahasiswa Fakultas Ekonomi Universitas Negeri Malang. Adapun populasi yang digunakan dalam mengukur tingkat pemahaman mahasiswa terhadap materi perkuliahan yang menggunakan Web Enhanced Course berjumlah 284 mahasiswa, sedangkan teknik pengambilan sampel yang digunakan proportional random sampling sehingga diperoleh sampel penelitian sebanyak 74 mahasiswa.

Tabel 1. Distribusi Sampel Menggunakan Metode Proportional Random Sampling

\begin{tabular}{ccc}
\hline No & Off & Distribusi dan Jumlah Sampel \\
\hline 1 & Q & $\frac{40}{284} \times 74=10,42(11)$ \\
2 & QQ & $\frac{42}{284} \times 74=10,94(11)$ \\
3 & O & $\frac{40}{284} \times 74=10,68(11)$ \\
4 & OO & $\frac{41}{284} \times 74=10,42(10)$ \\
5 & K & $\frac{40}{284} \times 74=10,68(11)$ \\
6 & KK & $\frac{40}{284} \times 74=10,42(10)$ \\
7 & KKK & $\frac{40}{284} \times 74=10,42(10)$ \\
\hline
\end{tabular}

Sumber: Data diolah peneliti, 2020 
Setelah sampel didistribusikan dengan memperhatikan populasi penelitian, maka langkah selanjutnya adalah dengan mengundi secara acak mahasiswa setiap kelompok kelas atau offering untuk dijadikan sampel.

\section{HASIL DAN PEMBAHASAN \\ Kemampuan Kognitif Peserta Didik}

Dari hasil pengolahan data penelitian yang diperoleh dari kuisioner yang telah dikumpulkan dari 74 responden yang tersebar di 7 offering atau kelas. Dari data kemampuan kognitif dapat diketahui bahwa kemapuan kognitif peserta didik memiliki skor terendah sebesar 40 dan skor tertinggi 52. Sedangkan mean sebesar 45,93, median sebesar 46 dan standar deviasi sebesar 2,01. Jumlah kelas dengan banyak data sampel sebesar 74 adalah 7 kelas dan kelas interval untuk masing-masing kelas adalah 2. Adapun distribusi frekuensi dari kemampuan kognitif yang digunakan untuk mengetahui pemahaman peserta didik terhadap materi perkuliahan dapat dilihat pada table 2 .

Tabel 2. Distribusi Frekuensi Variabel Kemampuan Kognitif Mahasiswa

\begin{tabular}{cccc}
\hline No & Interval & Frekuensi & Frekuensi Relatif (\%) \\
\hline 1 & $40-41$ & 1 & 1,35 \\
2 & $42-43$ & 5 & 6,77 \\
3 & $44-45$ & 23 & 31,08 \\
4 & $46-47$ & 32 & 43,24 \\
5 & $48-49$ & 10 & 13,51 \\
6 & $50-51$ & 1 & 1,35 \\
7 & $52-53$ & 2 & 2,70 \\
\hline & Jumlah & $\mathbf{7 4}$ & $\mathbf{1 0 0}$ \\
\hline
\end{tabular}

Sumber: Data diolah peneliti, 2020

Setelah mendapatkan distribusi frekuensi variable, maka langkah selanjutnya adalah dengan menghitung distribusi kecenderungan variable. Hal ini dimaksudkan untuk melihat pemahaman peserta didik terhadap materi perkuliahan berada pada kategori yang mana. Adapun distribusi kecendrungan variable kemampuan koginitif peserta didik terhadap kemampuan memahami materi perkuliahan dapat dilhat pada table 3 .

Tabel 3. Distribusi Kecenderungan Variabel Kemampuan Kognitif Peserta Didik

\begin{tabular}{cccccc}
\hline No & Interval & Frekuensi & $\begin{array}{c}\text { Frekuensi Relatif } \\
(\boldsymbol{\%})\end{array}$ & $\begin{array}{c}\text { Frekuensi } \\
\text { Kumulatif }\end{array}$ & Kategori \\
\hline 1 & $\mathrm{X} \geq 48$ & 13 & 17,57 & 17,57 & Tinggi \\
2 & $44 \leq \mathrm{X}<48$ & 55 & 74,32 & 91,89 & Sedang \\
3 & $\mathrm{X}<44$ & 6 & 8,11 & 100 & Rendah \\
\hline
\end{tabular}

Sumber: Data diolah peneliti, 2020

Dari pengolahan distribusi kecenderungan variable kemampuan kognitif pada Tabel 3, dapat disimpulkan bahwa sebagian besar peserta didik khususnya mahasiswa telah memenuhi indicator kemampuan kognitif, yaitu sebesar 74,32\%, yang artnya kemampuan kognitif peserta didik berada pada kategori sedang. Adapun kemampuan kognitif yang menunjang kemampuan peserta didik dalam pemahaman materi perkuliahan sudah berada pada tahap keterampilan intelektual dan strategi kognitif. Hal ini senada dengan konsep yang dikemukakan oleh Gagne dan Bloom yang menyatakan bahwa dalam proses pembelajaran terdapat hubungan antara kemampuan kognitif dengan taksonomi Bloom yaitu informasi verbal masuk ke kategori remember, keterampilan intektual masuk ke kategori understand dan apply, strategi kognitif masuk ke kategori analyze, evaluate dan 
create (Winkel, 2009). Adapun hubungan kemampuan kognitif dan taksonomi Bloom dapat dilihat dalam Gambar 1.

Gambar 1. Hubungan Kemampuan Kognitif Gagne dan Taksonomi Bloom

\section{Ranah Kognitif}

Bloom

1. Pengetahuan (Knowledge)

2. Pemahaman (Comprehension)

3. Penerapan (Application)

4. Analisis (Analysis)

5. Sintesis (Synthesis)

6. Evaluasi (Evaluation)

\section{Gagne}

a. Informasi verbal

b. Keterampilan intelektual (dibentuk konsep, kaidah) dan strategi kognitif

c. Strategi kogitif (menggunakan informasi, konsep dan kaidah)

Sumber: Winkel, 2009

Berdasarkan hubungan kemampuan kognitif Gagne dan Taksonomi Bloom diatas, maka dapat disimpulkan bahwa hasil penelitian ini telah menunjukkan bahwa peserta didik khususnya mahasiswa telah mampu untuk memahami materi perkuliahan dengan optimal dan menerapkannya dalam studi kasus yang diberikan oleh pendidik. Dukungan teoritis dari hasil penelitian ini juga diungkapkan oleh Basri (2018) yang menyakatan bahwa aktivitas di dalam proses belajar mengajar hendaknya ditekankan pada pengembangan struktur kognitif melalui pemberian kesempatan pada anak untuk memperoleh pengalaman langsung dalam berbagai aktivitas pembelajaran dengan pembelajaran terpadu. Hasil penelitian dari Amisyah dan Nurmaliah (2015) juga menghasilkan bahwa kemampuan memecahkan masalah akan mendorong semangat dan keinginan mahasiswa untuk belajar.

\section{Web Enhanced Course}

Dari hasil pengolahan data penelitian variable Web Enhanced Course dapat diketahui bahwa penggunaan media pembelajaran digital WEC dapat mempengaruhi pemahaman materi perkuliahan oleh peserta didik memiliki skor terendah sebesar 11 dan skor tertinggi 16. Sedangkan mean sebesar 14,01, median sebesar 14 dan standar deviasi sebesar 1,16. Jumlah kelas dengan banyak data sampel sebesar 74 adalah 7 kelas dan kelas interval untuk masing-masing kelas adalah 2. Adapun distribusi frekuensi dari pemahaman materi perkuliahaan dengan menggunakan media pembelajaran digital WEC dapat dilihat pada table 4.

Tabel 4. Distribusi Frekuensi Variabel Web Enhanced Course

\begin{tabular}{cccc}
\hline No & Interval & Frekuensi & Frekuensi Relatif (\%) \\
\hline 1 & $11-12$ & 8 & 10,81 \\
2 & $13-14$ & 34 & 45,95 \\
3 & $15-16$ & 32 & 43,24 \\
4 & $17-18$ & 0 & 0 \\
5 & $19-20$ & 0 & 0 \\
6 & $21-22$ & 0 & 0 \\
7 & $23-24$ & 0 & 0 \\
\hline & Jumlah & $\mathbf{7 4}$ & $\mathbf{1 0 0}$ \\
\hline
\end{tabular}

Sumber: Data diolah peneliti, 2020

Setelah mendapatkan distribusi frekuensi variable, maka langkah selanjutnya adalah dengan menghitung distribusi kecenderungan variable. Hal ini dimaksudkan untuk 
melihat penggunaan media pembelajaran digital WEC dapat mempengaruhi pemahaman materi perkuliahan oleh peserta didik berada pada kategori yang mana. Adapun distribusi kecendrungan variable pemahaman materi perkuliahaan dengan menggunakan media pembelajaran digital WEC dapat dilihat pada table 5.

Tabel 5. Distribusi Kecenderungan Variabel Web Enhanced Course

\begin{tabular}{cccccc}
\hline No & Interval & Frekuensi & $\begin{array}{c}\text { Frekuensi Relatif } \\
(\boldsymbol{\%})\end{array}$ & $\begin{array}{c}\text { Frekuensi } \\
\text { Kumulatif }\end{array}$ & Kategori \\
\hline 1 & $\mathrm{X} \geq 15$ & 32 & 43,24 & 43,24 & Tinggi \\
2 & $13 \leq \mathrm{X}<15$ & 34 & 45,95 & 89,19 & Sedang \\
3 & $\mathrm{X}<13$ & 8 & 10,8143, & 100 & Rendah \\
\hline & Jumlah & $\mathbf{7 4}$ & $\mathbf{1 0 0}$ & & \\
\hline
\end{tabular}

Sumber: Data diolah peneliti, 2020

Dari pengolahan distribusi kecenderungan variable pemahaman materi perkuliahan dengan menggunakan media pembelajaran digital WEC pada Tabel 5, dapat disimpulkan bahwa sebagian besar peserta didik khususnya mahasiswa telah memenuhi indicator penggunaan media pembelajaran digital WEC dalam memahami materi perkuliahan, yaitu sebesar 45,95\%. Artinya, WEC mampu mengakomodir kemampuan kognitif siswa sehingga mampu untuk memahami materi perkuliahan dengan lebih mudah. Hal ini senada dengan pendapat Sa'ud (2009) yang menyatakan bahwa WEC merupakan pemanfaatan internet untuk pendidikan, selain itu dapat juga digunakan untuk menunjang peningkatan kualitas belajar mengajar di kelas.

Berdasarkan hasil pengolahan data diatas, maka dapt disimpulkan bahwa Web Enhanced Course dapat digunakan sebagai salah satu media pembelajaran yang dapat menunjang peningkatan kualitas pembelajaran di kelas dengan konsep sebagian materi disampaikan melalui internet, dan sebagian lagi melalui tatap muka, sehingga tingkat pemahaman peserta didik terhadap maeri perkuliahan akan lebih kompleks. Hal ini senada dengan hasil penelitian Karo-karo \& Rohani (2018) yang menyatakan bahwa media merupakan suatu alat atau sarana sebagai perantara untuk menyampaikan bahan pelajaran dari guru kepada anak didik

Tujuan dari penelitian ini adalah untuk mengetahui apakah media pembelajaran digital menggunakan Web Enhanced Course dapat meningkatkan pemahaman peserta didik terhadap materi perkuliahan yang diukur menggunakan indicator kemampuan kognitif peserta didik. Dari hasil uji statistic diperoleh kooefesien korelasi (R) variable Web Enhanced Course terhadap variable pemahaman materi perkuliahan yang diambil dari kemampuan kognitif sebesar 0,238. Artinya variable Web Enhanced Course memiliki hubungan (berkolerasi) sebesar 0,238 atau 23,8\% terhadap pemahaman materi perkuliahan yang diambil dari kemampuan kognitif peserta didik. Sedangkan kooefisien deteminasi $\left(\mathrm{R}^{2}\right)$ sebesar 0,05. Artiya, variable Web Enhanced Course berpengaruh terhadap variable pemahaman materi perkuliahan yang diambil dari kemampuan kognitif sebesar 5\%. Dari hasil ini, maka dapat diketahui bahwa pemahaman materi oleh peserta didik dipengaruhi oleh penggunaan media pembelajaran digital Web Enhanced Course. Semakin sering pendidik menggunakan menggunakan media pembelajaran digital Web Enhanced Course, maka akan semakin tinggi tingkat kemampuan pemahaman terhadap materi perkuliahan yang diukur dari kognitif peserta didik. Hal ini sesuai dengan hasil penelitian yang dilakukan oleh Tafanao (2018) yang menyatakan bahwa media pembelajaran perlu dimanfaatkan secara sinergis untuk mengoptimalkan pembelajaran.

Taraf signifikasi atau linieritas dari penelitian ini diperoleh angka sebesar 0,04. Artinya, nilai Sig. < kriteria signifikansi, yaitu $0,04<0,05$, hal ini menunjukkan bahwa 
data yang telah diolah dari penelitian ini memenuhi kriteria linieritas. Adapun persamaan regresi dari hasil pengolahan data pada penelitian ini dapat dirumuskan sebagai berikut:

$$
Y=40,92+0,35 X
$$

Dari persamaan regresi diatas, maka dapat diartikan bawa setiap adanya peningkatan penggunaan media pembelajaran digital Web Enhanced Course maka akan diikuti terjadinya peningkatan kemampuan pemahaman terhadap materi perkuliahan dengan besaran yang sama. Dikarenakan koofesien regresi bertanda + , artinya dalam penelelitian ini, setiap kali ada peningkatan pada salah satu variable maka akan diikuti peningkatan variable lainnya.

Penggunaan media pembelajaran dalam proses kegiatan belajar mengajar merupakan variable penentu keberhasilan dalam transfer ilmu pengetahuan selain metode yang digunakan pendidik dalam menyampaikan materi. Hal ini didukung dengan pendapat Arsyad (2010) yang menyatakan bahwa media pembelajaran merupakan alat yang digunakan dalam menyampaikan atau mengantarkan pesan-pesan pengajaran. Karena dengan semakin bervariasinya model dan metode pengajaran yang digunakan pendidik, maka akan semakin memberikan motivasi kepada peserta didik dalam menerima pesan da isi materi perkuliahan. Selain ketepatan penmilihan media pembelajaran yang digunakan, juga dipengaruhi oleh interaksi yang positif antara pendidik dan peserta didik. Hal ini sesuai dengan pendapat Saputra (2019) yang menyatakan bahwa proses pembelajaran di dalam kelas dapat berlangsung efektif apabila ada interaksi antara guru dan siswa.

\section{KESIMPULAN}

Berdasarkan hasil penelitian, maka dapat disimpulkan bahwa penggunaan media pembelajaran digital Web Enhanced Course memiliki pengaruh terhadap peningkatan pemahaman materi perkuliahan oleh peserta didik yang diukur menggunakan kemampuan kognitif. Adapun saran dari hasil penelitian ini adalah pendidik diharapkan sering untuk menggunakan media dan model pembelajaran yang lebih variatif dalam mentransfer ilmu sehingga pesan yang disampaikan kepada peserta didik dapat dipahami secara tuntas. Sedangkan saran yang dapat disampaikan bagi penelti selanjutnya adalah agar dilakukan penelitian reflikasi dengan menambah variable-variabel pendukung lainnya yang mempengaruhi kemampuan peserta didik dalam memahami materi perkuliahan. Hal ini dimaksudkan agar diketahui variable mana yang akan lebih berpengaruh terhadap proses pemahaman materi perkuliahan oleh peserta didik.

\section{REFERENSI}

Abdurrahman, M (2012) Anak Berkesulitan Belajar. Jakarta: Rineka Cipta.

Aimsyah, S., dan Nurmaliah, C (2015) Upaya Peningkatan Hasil Belajar Kognitif melalui Model Probelem Based Learning. BIOTIK: Jurnal Ilmiah Biologi Teknologi dan Kependidikan, 1(2), 87-92.

Arsyad, A. (2010) Media Pembelajaran. Jakarta: Raja Grafindo Persada.

Basri, H (2018) Kemampuan Kognitif dalam Meningkatkan Efektivitas Pembelajaran Ilmu Sosial Bagi Siswa Sekolah Dasar. Jurnal Penelitian Pendidikan, 18(1), 1-9.

Departemen Pendidikan Nasional (2012) Pedoman Pembelajaran Bidang Pengembangan Kognitif di Taman Kanak-Kanak. Jakarta: Direktorat Pembinaan Taman KanakKanak dan Sekolah Dasar.

Karo-Karo, I.R dan Rohani (2018) Manfaat Media dalam Pembelajaran. Jurnal Pendidikan dan Matematika (AXIOM), 7(1), 91-96. 
Mitasari, N.R (2018) Model Pembelajaran Edutaiment dalam Perkembangan Kognitif Siswa Sekolah Dasar. Jurnal Cakrawala Pendas, 4(1), 41-49.

Priyambodo, E.P., Wiyasari, A., dan Sari, Rr.L.P (2012) Pengaruh Media Pembelajaran Interaktif Berbasis WEB terhadap Motivasi Belajar Mahasiswa. Jurnal Kepedidikan, 42(2), 99-109.

Sa'ud, U.S (2009) Inovasi Pendidikan. Bandung: Alfabeta.

Saputra, H.N (2019) Analisis Respon Guru dan SIswa terhadap Penenrapan Model Siklus Belajar Hipotesis Deduktif. Jurnal Pedagogik, 6(2), 278-299.

Solihat, A.N., Suminawati, Afriza, E.F (2019) Implementasi Pedagogical Content Knowledge (PCK) dalam Meningkatkan Kemampuan Kognitif Siswa. Jurnal Ekonomi Pendidikan dan Kewirausahaan, 7(1), 69-76.

Susanto, A (2011) Perkembangan Anak Usia Dini. Jakarta: Kencana.

Suwastika, I. W. K. (2018). Pengaruh E-Learning Sebagai Salah Satu Media Pembelajaran Berbasis Teknologi Informasi Terhadap Motivasi Belajar Mahasiswa. Jurnal Sistem Dan Informatika (JSI), 13(1), 1-5.

Tafano, T (2018) Peran Media Pembelajaran dalam Meningkatkan Minat Belajar Mahasiswa. Jurnal Komunikasi Pendidikan, 2(2), 103-114.

Winkel, W.S. (2009) Psikologi Pengajaran. Jogjakarta: Media Abadi.

Yamin, M (2008) Paradigma Pendidikan Konstruktivistik. Implementasi KTSP dan UU No. 14 Tahun 2005 Tentang Guru dan Dosen. Jakarta: Gaung Pers. 